\title{
Structure of the Extruded and Thermally Treated $\mathrm{Ni}_{54.3} \mathrm{Fe}_{16.2} \mathrm{Ga}_{29.5}$ Alloy
}

\author{
K. Prusik*, E. Matyja, M. Zubko And T. GoryczkA \\ University of Silesia, Institute of Materials Science, Bankowa 12, 40-007 Katowice, Poland
}

\begin{abstract}
Hot extrusion process was applied to $\mathrm{Ni}_{54.3} \mathrm{Fe}_{16.2} \mathrm{Ga}_{29.5}$ polycrystalline alloy. Then the rod was annealed subsequently for $1 \mathrm{~h}$ at $700,800,900$, and $1100^{\circ} \mathrm{C}$. In this paper the effect of annealing on the microstructure of the polycrystalline extruded $\mathrm{Ni}-\mathrm{Fe}-\mathrm{Ga}$ alloy were analyzed. The structure of the alloys was determined by the X-ray and transmission electron microscopy. The electron backscattering diffraction technique was applied to obtain the texture of the extruded rods after heat treatment.
\end{abstract}

DOI: 10.12693/APhysPolA.130.1020

PACS/topics: 81.30.Kf, 87.64.Ee, 81.30.Mh, 83.85.Hf, 71.20.Lp, 71.20.Be

\section{Introduction}

Ferromagnetic shape memory alloys (FSMA) are relatively new group of promising magnetic actuator materials for which under the external magnetic field the magnetic-field-induced strain (MFIS) occurs. Until now several alloy systems have been developed as FSMA, e.g. Ni-Mn-Ga [1], Ni-Mn-In [2], Co-Ni-Ga [3, 4], Fe-Pt, $\mathrm{Co}-\mathrm{Ni}-\mathrm{Al}, \mathrm{Fe}-\mathrm{Pd}$, and $\mathrm{Ni}-\mathrm{Fe}-\mathrm{Ga}$ [5]. In single crystalline $\mathrm{Ni}-\mathrm{Mn}-\mathrm{Ga}$ alloys MFIS may even reach over $10 \%$ of longitudinal strain [1]. This large effect is easy to obtain in single crystals with microstructure of multiple martensite variants, provided that they are subjected to a necessary training process [6]. In the polycrystalline alloys due to the statistical orientation of the grains MFIS effect is practically not observed. In other to improve the orientation of the grains the alloys are produced, for instance, by directional solidification, processed by high temperature plastic deformation methods [7], extrusion [8, 9], etc. In this paper the effect of annealing on the microstructure of the polycrystalline $\mathrm{Ni}-\mathrm{Fe}-\mathrm{Ga}$ extruded alloy was analyzed. The $\mathrm{Ni}_{54.3} \mathrm{Fe}_{16.2} \mathrm{Ga}_{29.5}$ (at.\%) ingot obtained by induction melting was extruded and subsequently annealed at $700-1100^{\circ} \mathrm{C}$.

\section{Experimental procedure}

The polycrystalline $\mathrm{Ni}_{54.3} \mathrm{Fe}_{16.2} \mathrm{Ga}_{29.5}$ (at.\%) alloy was prepared from the metallic elements $\mathrm{Ni}$, Fe $(99.99 \% \mathrm{pu}-$ rity) and Ga (99.999\% purity) by melting in an induction furnace in argon atmosphere and cast into the mould. The round ingot were extruded into rods of $10 \mathrm{~mm}$ diameter with the reduction rate of $75 \%$ (Fig. 1). To be sure that the extrusion process was carried out in the B2 phase state the die was heated to the $700{ }^{\circ} \mathrm{C}$.

The extruded rod was cut into slices. Subsequently, each slice was encapsulated separately in the quartz tube

\footnotetext{
*corresponding author; e-mail: krystian.prusik@us.edu.pl
}

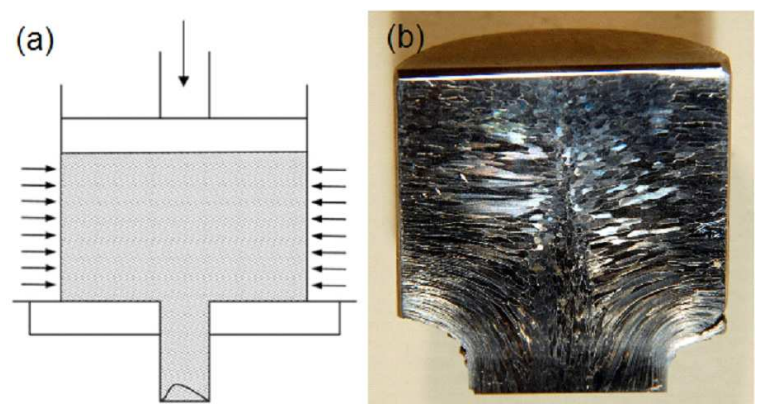

Fig. 1. Scheme of extrusion (a) and macrostructure of the transient zone (b).

then annealed for $1 \mathrm{~h}$ at $700,800,900$, and $1100^{\circ} \mathrm{C}$ and quenched into water. After annealing the specimens were cut in a rectangular shape along the extrusion direction. The microstructure of the specimens was examined by optical microscopy and scanning electron microscopy (SEM) JEOL JSM-6480. Structure of the phases was studied by X-ray diffraction (XRD) (Philips Expert) and the high resolution transmission electron microscope (TEM) JEM 3010 operated at $300 \mathrm{kV}$. Thin foil for the TEM studies were prepared by GATAN PIPS ion polisher. The chemical composition of the alloy was determined by the energy dispersive spectrometer (EDS) IXRF attached to the SEM applying the standard calibration method. Texture measurements were performed by the HKL EBSD Channel 5 system equipped with the Nordlys II camera.

\section{Results and discussion}

Figure 1 shows scheme of extrusion and macrostructure of the transient zone. One can see that in the nonextruded (upper) part of the ingot, columnar grains perpendicular to the rod's axis are present. During extrusion, rotation of the grains on the rod axis direction were observed (Fig. 1b). For each sample annealed at 700$1100^{\circ} \mathrm{C}$ similar microstructure with strongly dispersed precipitates of the second phase in the matrix appeared (Fig. 2a-d). 

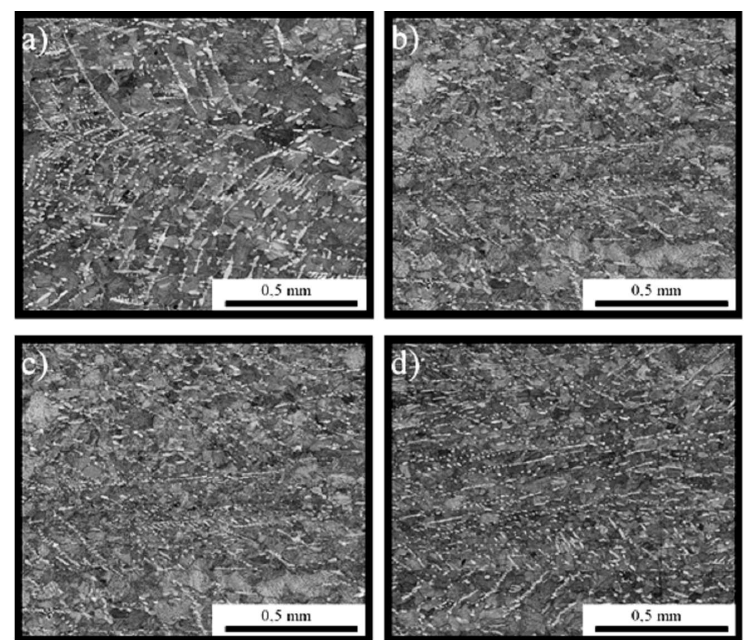

Fig. 2. Microstructure of the extruded rod of samples heat treated at: $1100{ }^{\circ} \mathrm{C}$ (a), $900^{\circ} \mathrm{C}$ (b), $800^{\circ} \mathrm{C}$ (c), $700^{\circ} \mathrm{C}(\mathrm{d})$.

The amount of the precipitates does not depend on the applied heat treatment. Chemical composition measured by EDS revealed that the precipitates contain more $\mathrm{Fe}$ and less Ga than the matrix (Fig. 3). The results of the chemical composition measurements of the matrix and the precipitates versus annealing temperatures are depicted in Table I. The chemical composition of the matrix and precipitates do not change in terms of applied annealing temperature. The precipitates consist of about 10 at.\% less gallium and 7 at.\% more iron than the matrix, whereas the $\mathrm{Ni}$ content of the matrix and precipitates differs about 2 at.\%.
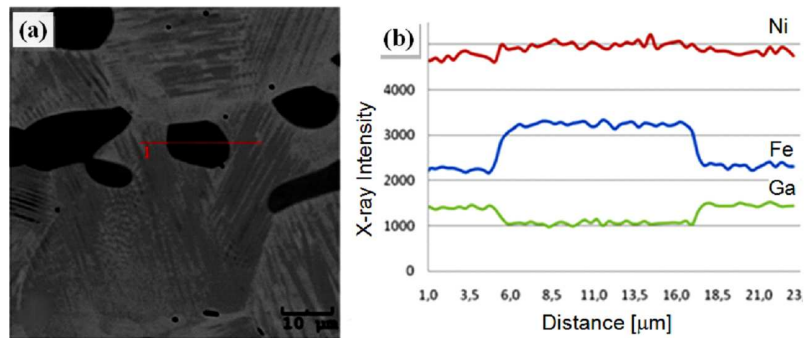

Fig. 3. SEM image of the extruded rod (a) and the X-ray intensity line profile (b) across the precipitate indicated in (a).

The X-ray diffraction (Fig. 4) shows that the as-cast sample and annealed one consist of two phases: $14 \mathrm{M}$ martensite (denoted also as 7M) of the monoclinic structure $\left(a_{0}=4.2477 \AA, b_{0}=5.3469 \AA, c_{0}=29.0902 \AA\right.$, $\left.\alpha=\gamma=90^{\circ}, \beta=92.8^{\circ}\right)$ and $\gamma$ precipitates of the cubic structure $\left(a_{0}=b_{0}=c_{0}=3.590 \AA, \alpha=\beta=\gamma=90^{\circ}\right)$. To determine the unit cell parameters of the martensite phase the Rietveld refinement was applied.

Texture measurements was performed by electron backscattering diffraction (EBSD) which is excellent

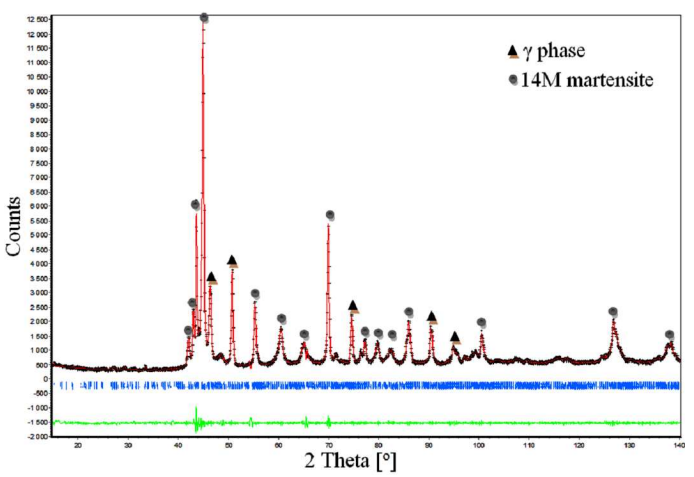

Fig. 4. X-ray diffractogram of the extruded sample. a)
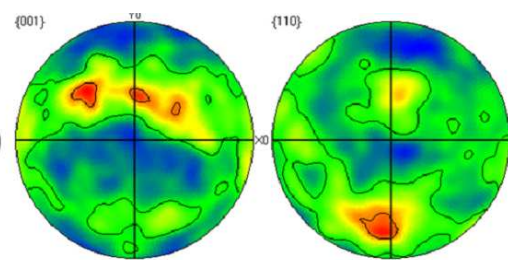

b)
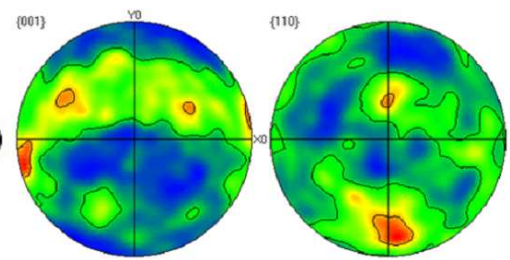

c)
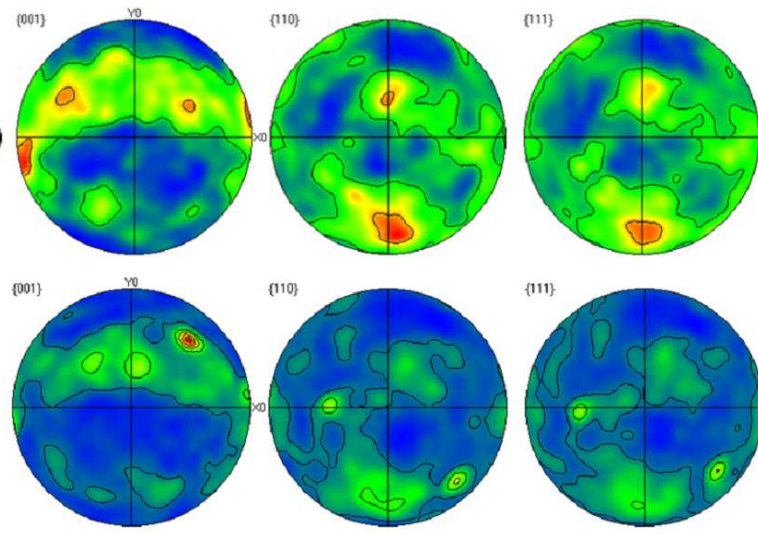

d)
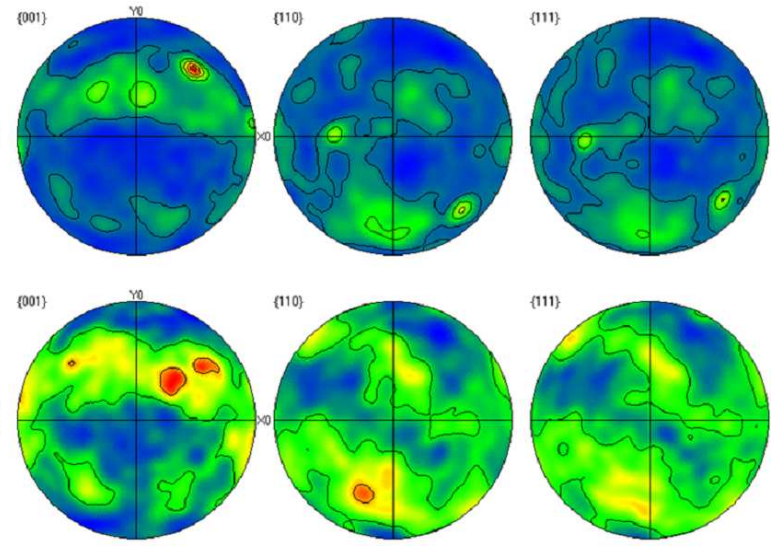

Fig. 5. EBSD $\{001\},\{110\}$ and $\{111\}$ pole figures of the matrix for samples annealed for $1 \mathrm{~h}$ at: $1100^{\circ} \mathrm{C}(\mathrm{a})$, $900^{\circ} \mathrm{C}(\mathrm{b}), 800^{\circ} \mathrm{C}(\mathrm{c}), 700^{\circ} \mathrm{C}(\mathrm{d})$.

technique to analyze grains orientation in metals and alloys and widely used in structural analysis of minerals [10]. The distribution of the orientations in the matrix pole figures shows that all specimens are strongly textured polycrystalline materials (Fig. 5).

One can see that in the matrix $\langle 001\rangle$ fiber texture rotates about $30^{\circ}$ around $X$ axis. Applied thermal treatment did not affect much the type of texture present in the samples. Even in the specimen annealed at $1100^{\circ} \mathrm{C}$ the same type of texture was observed. 


\section{TABLE I}

Chemical composition [at.\%] of the matrix and precipitates versus annealing temperature $T\left[{ }^{\circ} \mathrm{C}\right]$.

\begin{tabular}{c|c|c|c|c}
\hline \hline Area & $T$ & $\mathrm{Fe}$ & $\mathrm{Ni}$ & $\mathrm{Ga}$ \\
\hline \multirow{5}{*}{ matrix } & 1100 & 15.2 & 53.5 & 31.3 \\
& 900 & 15.0 & 53.6 & 31.4 \\
& 800 & 15.1 & 53.5 & 31.4 \\
& 700 & 15.1 & 53.3 & 31.6 \\
\hline \multirow{5}{*}{ precipitate } & 1100 & 22.4 & 55.7 & 21.9 \\
& 900 & 23.0 & 56.0 & 21.0 \\
& 800 & 22.4 & 55.8 & 21.8 \\
& 700 & 22.7 & 55.3 & 22.0
\end{tabular}
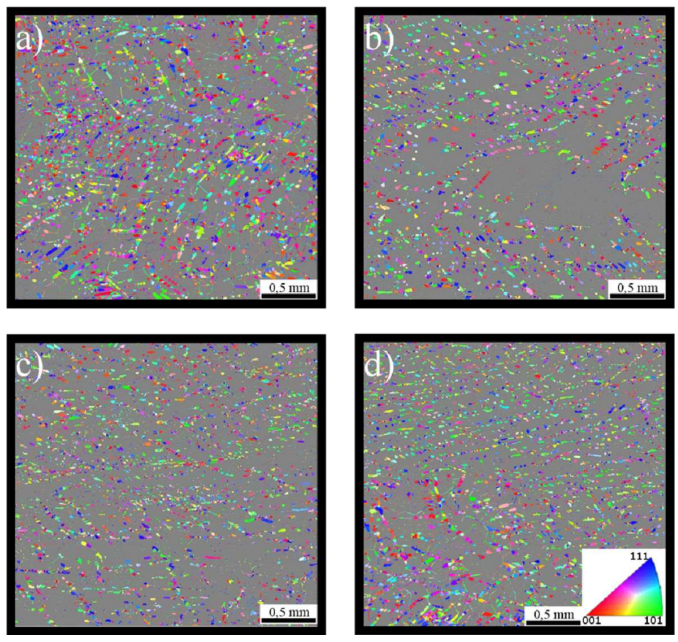

Fig. 6. OIM of the precipitates for samples annealed for $1 \mathrm{~h}$ at: $1100{ }^{\circ} \mathrm{C}(\mathrm{a}), 900^{\circ} \mathrm{C}(\mathrm{b}), 800{ }^{\circ} \mathrm{C}(\mathrm{c}), 700^{\circ} \mathrm{C}(\mathrm{d})$.

In all specimens the precipitates were randomly oriented in the matrix (Fig. 6). In the orientation image map (OIM) and pole figures of the precipitates no texture and/or any specific crystallographic orientation relationships between the matrix and the precipitates were confirmed.

\section{Summary}

Hot extrusion process was successfully applied to $\mathrm{Ni}_{54.3} \mathrm{Fe}_{16.2} \mathrm{Ga}_{29.5}$ polycrystalline alloy. The obtained rod shows $\langle 001\rangle$ fiber texture rotated about $30^{\circ}$ around $X$ axis. Then the rod was cut into slices and annealed for $1 \mathrm{~h}$ at $700,800,900$, and $1100^{\circ} \mathrm{C}$. In all thermally treated specimens two-phase microstructure (martensite $14 \mathrm{M}+\gamma$ precipitates) was observed. The $\langle 001\rangle$ fiber texture rotation about $30 \circ$ around $X$ axis was confirmed. Applied thermal treatment did not destroyed the texture present in the sample. Iron and nickel rich $\gamma$ precipitates were randomly oriented in the matrix - no crystallographic orientation relations between the matrix and the precipitates were confirmed.

\section{Acknowledgments}

We would like to thank to Krzysztof Bystrzykowski for his contribution and specimen preparation and Professor Henryk Morawiec for fruitful discussion.

\section{References}

[1] A. Sozinov, A.A. Likhachev, N. Lanska, K. Ullakko, Appl. Phys. Lett. 80, 1746 (2002).

[2] R. Kainuma, Y. Imano, W. Ito, Y. Sutou, H. Morito, S. Okamoto, O. Kitakami, K. Oikawa, A. Fujita, T. Kanomata, K. Ishida, Nature 439, 957 (2006).

[3] K. Prusik, B. Kostrubiec, T. Goryczka, G. Dercz, P. Ochin, H. Morawiec, Mater. Sci. Eng. A 481482, 330 (2008).

[4] K. Prusik, H. Morawiec, B. Kostrubiec, M. Prewendowski, G. Dercz, K. Ziewiec, Eur. Phys. J. Spec. Topics 158, 155 (2008).

[5] M.L. Corróa, S. Kustov, E. Cesari, Y.I. Chumlyakov, Mater. Sci. Eng. A 521-522, 201 (2009).

[6] R. Chulist, W. Skrotzki, C.-G. Oertel, A. Böhm, H.-G. Brokmeier, T. Lippmann, Int. J. Mater. Res. 103, 575 (2012).

[7] H. Morawiec, T. Goryczka, A. Drdzeń, J. Lelątko, K. Prusik, Solid State Phenom. 154, 133 (2009).

[8] K. Prusik, K. Bałdys, D. Stróż, T. Goryczka, J. Lelątko, Solid State Phenom. 203-204, 306 (2013).

[9] A. Böhm, S. Roth, G. Naumann, W.-G. Drossel, R. Neugebauer, Mater. Sci. Eng. A 481-482, 266 (2008).

[10] I.O. Galuskina, E.V. Galuskin, T. Armbrusteter, B. Lazic, J. Kusz, P. Dzierżanowski, V.M. Gazeev, N.N. Pertsev, K. Prusik, A.E. Zadov, A. Winiarski, R. Wrzalik, A.G. Gurbanov, Am. Miner. 95, 1172 (2010). 